successful treatment requires the doctor to use the information publicly to organise the necessary resources. On the matter of patient access to records, Macara and Francis steer a middle course between unrestricted access and absolute secrecy, and argue for 'modified access'. Under this, patients should be allowed to see their records, unless the health professional bars access on the grounds that the disclosure threatens harm to the patient or poses third party problems. If the patient is unsatisfied she or he can request some kind of second opinion. Such a proposal found no favour either with the BMA or the Government, despite the fact that the position of both seems to conflict with the spirit of the Act.

A final chapter by David Watson seeks to draw attention to the ethical issues which underlie the previous, more practical discussions. Rights to information, he contends, must be grounded upon a clearly established concept of privacy and the rights attached to it. He succeeds in raising some important questions about the value placed on confidentiality and privacy, linking them to an individualist ethic. As the questions proliferate, though, the arguments get rather lost, and the chapter might have benefited from a more focused approach.

The same might be said of the book as a whole. There are some unnecessary repetitions (especially since this is a short book). More seriously, the volume lacks both an introduction and conclusion, and the reader is left without any clear sense of direction. This is a pity because the book addresses an important topic, and begs some crucial questions about the way in which professional ethics need to be defined in relation to the collection and transmission of information.

JOHN STREET

Lecturer in Politics

School of Economic and Social Studies University of East Anglia

\section{Measuring Health: a Practical Approach}

Edited by George Teeling-Smith, 268 pages, Great Britain, £26.50, John Wiley and Sons, 1988

With the demand for health care apparently infinite and its supply finite, harsh choices are inevitable. With demand increasing due to demographic pressures and rapid technological advance, especially in molecular biology, decision-makers in the health care system, be they politicians, managers or clinicians, are having to deprive patients of care from which they could benefit in terms of enhancements in their length and quality of life.

What criteria should these decisionmakers use when making such life-anddeath decisions in a world in which most health care therapies have not been evaluated thoroughly and where there is little agreement about how to measure health? The authors of the chapters of this book seek to clear the jungle around the base camp of this long climb up the Eiger!

After an editorial introduction, Sonja Hunt discusses the merits of one health measure, the Nottingham Health Profile (NHP). Paul Kind in chapter 3 reviews the strength and weaknesses of the NHP and other measures of the quality of life which have been developed in North America and the UK. Gillian Capewell offers another review of this difficult area in chapter 4 and then Martin Buxton and Joy Ashby report some results of using the timetrade-off method. Further examples of applications of these measures are presented in a series of chapters on Parkinson's Disease (Welburn and Walker), cancer (Schepper and Clinch), rheumatoid arthritis (Patterson), heart disease (O'Brien) and irritable bowel syndrome (Stevens, Poston and Walker). The authors of final chapters examine applications in management (Williams) and clinical practice (Roberts).

Because of finite health care resources, competing health care activities, preventive, diagnostic and treatment, have to be prioritised. How do the attempts to measure health which are reported in this book facilitate prioritisation?

There are clearly many ways in which the quality of life can be measured. 'Guesstimates' of the effects of competing therapies on the quality of life (QoL) can be combined with poor data on post operative/treatment survival to construct estimates of quality adjusted life years (QALYs). Both the ingredients, estimates of the QoL and survival, are crude. However, they do produce an explicit judgement and the challenge is how to improve the accuracy of this judgement.

This book shows quite clearly there is no 'gold standard' for measuring health. However, the work reported here demonstrates that progress is being made and that guidance for decisionmakers can be produced by careful and patient application of measurement instruments which are gradually being tested and improved.

ALAN MAYNARD

Professor of Health Economics Centre for Health Economics University of York Heslington, York YOI 5DD

\section{Human Genetic Information: Science, Law and Ethics}

Ciba Foundation Symposium, $\mathrm{x}+212$ pages, Chichester, £35.95, John Wiley and Sons, 1990

The 40th anniversary of the Ciba Foundation was marked by celebrations in June 1989 which included this symposium. Twelve papers, plus an introduction and summing-up from $\mathrm{Sir}$ Gustav Nossal, the chairperson, cover recent developments in human genetics from a variety of perspectives scientific, legal, religious and philosophical. The discussion following each paper is reproduced, and contains some of the most valuable points in what is a very worthwhile volume. Various ethical positions are discussed, including the relative merits of the language of interests and the language of rights (pages 105-106).

The issues fall into four categories: the first three concern the acquisition of human genetic information, the communication of this information, and its applications. The fourth concerns the wider religious and philosophical significance of human genetics.

In the first category, the possibility that some research could lead to 'dangerous knowledge' and should therefore be prohibited is rejected (page 75). Whether it is worthwhile to attempt to sequence the entire human genome, however, is considered by Sydney Brenner. He argues that since 98 per cent of the human genome is 'junk', the important 2 per cent should be sequenced first. In the ensuing discussion he agrees that the primary justification for the work is medical benefit.

Turning to communication, there is concern that 'the public' is viewed as an uninformed body to whom the scientific 
community must 'sell' their knowledge (page 196). Further problems concern the interests of individuals. Walter Zimmerli asks who has the right to know ther genetic constitution of a person and discusses the competing views that the individual has a moral right to genetic privacy and that information is not something that can be privately owned. Zimmerli attempts to resolve the problem via a distinction between 'strictly private' and 'publicly accessible' data (page 99).

The papers of Diana Brahams and of Norman Carey and P E Crawley include a discussion of the patenting of genetic information. Discussion focuses on whether the system limits or facilitates access to information that ought, in Zimmerli's terms, to be publicly accessible. Bernard Davis suggests that patents monopolise, not knowledge, but the use of it.

The greatest controversy might be expected regarding the possible applications of genetic information. Paul Debenham's paper on DNA fingerprinting, however, claims that this, at least, raises no new issues of principle.

While recent press coverage has concentrated on the potential for gene therapy, John Bell's paper claims that prenatal diagnosis followed by selective termination has had the most profound impact of any health measure since immunisation (page 19). Bernard Davis agrees, arguing that it will continue to be simpler and safer than germline gene therapy (page 86).

Only the somatic version of gene therapy wins wide support, for treating monogenic disease. In future, however, polygenic disease will be increasingly researched. Bell suggests that postbirth screening for this would permit affected individuals to modify their lifestyles (page 25). A similar, environmental, approach is suggested by Williamson and Kessling (page 65 ). Gurling's paper, about the genetics of psychiatric disorder, also suggests that genetic research may point to ways in which the environment should be changed (page 55). The opposition between genes and environment runs through the collection, Williamson points out the mistake of thinking about this in simple terms, because both genetic and environmental influence can be broken down into components (page 73).

The final three papers look at religious and philosophical questions. Rihito Kimura looks at how different religions accept genetic intervention to relieve suffering; Bernard Williams examines the implications of genetic information for personal identity and parental pride; Max Charlesworth criticises attempts to derive a theory of human nature from genetics itself.

RUTH F CHADWICK

Lecturer in Philosophy and Director of the Centre for Applied Ethics University of Wales College of Cardiff

\section{Doctors' Decisions: Ethical Conflicts in Medical Practice}

Edited by G R Dunstan and E A

Shinebourne, $x+248$ pages, Oxford, $£ 22.50$, OUP, 1989

This very useful book consists of twentytwo essays by twenty-five contributors, drawn mainly from the UK, especially London and Cambridge, with one each from Australia, the Republic of Ireland and the USA. The point of it is to listen to medical folk giving an account of ethical decisions they have had to face in their different professional capacities. The chapters move from issues involved in experiments on animals, through prenatal decisions, those in neonatal care, in dealing with adolescent girls, students, those suffering from sexuallytransmitted diseases, those arising in clinical oncology, in psychiatry and psychotherapy in the pharmaceutical industry, in intensive and in terminal care, in the general care of the elderly, to those in general practice.

In the first chapter Professor Dunstan makes clear that the need for the book arises from the explosion of interest in medical ethics. Sociologists, lawyers, philosophers, theologians, economists and the general public are involved in the discussions, and if medical ethics can no longer be left solely to the medical profession it cannot be studied without conceding that members of that profession must be given a primary place in decisionmaking: it is inherent in their professional role.

The book includes a chapter by a Christian theologian and moral philosopher, one by a Rabbi, and one by a philosopher, who concludes it by commenting on many of the issues raised. He stresses the need for a public social morality to be related to the reflective work in medical ethics lest contradictions and confusions arise in the public mind and the legal system. An example is the legal or quasi-legal status of the embryo in vitro and in vivo.

Several frequently discussed issues are raised, sometimes in more than one chapter: the meaning of informed consent; confidentiality in the doctorpatient relationship and its relation to other obligations; clinical autonomy, in the setting of the moral norms of society, concerning the beginning and end of life; the extent to which qualityof-life considerations are ethically relevant, and problems in the allocation of relatively scarce resources.

On what basis are decisions to be made? How far is there likely to be common agreement? A lot depends on how flexible the different bases are in operation. Rabbi Bleich's chapter shows Jewish ethics often coinciding with convictions widely held on various other grounds, but not always, and where they do not, agreement may not be easy because it may seem to others to depend on very strained interpretations of biblical texts. Some Christians are inflexible, but Helen Oppenheimer writes sensitively against interpreting phrases like 'we must not play God' or 'the sanctity of life' in a rigid manner. She shows how Christian theology can underpin at a deep level decisions reached on other grounds. The editor of this journal, Raanan Gillon, outlines four prima facie principles which are 'defensible from a wide variety of moral perspectives, religious and secular, utilitarian and deontological, virtue based or principle based'. They are (1) respect for autonomy, (2) the principle of beneficence, (3) the principle of nonmaleficence and, (4) the principle of justice as fairness. This is in sharp contrast to some moral philosophers who are telling us that our pluralistic societies have no common understanding of a moral vocabulary, and thus have no means of meaningfully discussing, let alone resolving, moral issues. Reading this book might make them think again. However the fact that Gillon's four principles are prima facie ones means that they cannot be applied woodenly. Discernment in particular cases will always be needed. Certainty in ethical judgements, which many crave, cannot be had.

RONALD PRESTON Emeritus Professor of Social and Pastoral Theology, Manchester University, 161 Old Hall Lane Manchester M14 6Hf 